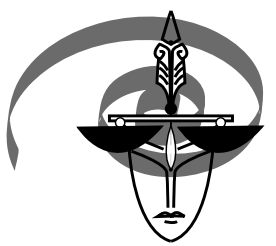

DOI: 10.1515/ep-2016-0013

Nathan J. Gordon*

\title{
A Field Polygraph Examination: Science or Art?**
}

Полиграфические исследования на практике. Наука или искусство?

Key words: Polygraph Examination, Utah Zone Comparison Test, Meta-Analytic Survey of Criterion Accuracy of Validated Polygraph Techniques

Recently I was asked to control the quality of a polygraph examination for a prosecutor performed on a suspect accused of molesting two young children. The polygraph performed for the defence was conducted by a high-profile academically recognised

\footnotetext{
* e-mail: nategordon@isope.net

** From the editor: The case seems obvious from the point of view of scientific methodology, and raises no doubts as such. Any individual polygraph examination, like any post-mortem or any expertise from the scope of forensic sciences, belongs to art. An art that is based on the achievements of science and results of scientific research. It is science that lays the foundation of the method that is applied and accepted as evidence. Its use in a specific case (expert opinion, including a polygraph examination) must conform to rules - state of the art. State of the art results from the achievements of science and practical experience. Practice, in turn, again undergoes the assessment of science. Thus, to recapitulate: a polygraph examination in a specific case works within the realm of art. The art of applying the achievements of science to every individual case.
} 
examiner. The technique used was the modified Utah Zone Comparison Test, which resembles the AFMGQT2, a "C R R C R R C" format. Even if there was research validating the technique, which I am not aware of, how could the "artistic" ability or "quality" of such examination be taken into question?

The test was performed twice. The first test consisted of five (5) charts, making use of directed lie comparison questions (DLCQ).The actual questions are presented below, although the actual names have been eliminated:

1. Do you understand I will ask only the questions we have discussed?

2. Do you intend to answer truthfully all the questions about allegations that you sexually abused [Victim 1] and [Victim 2]?

3. Is your name [first name used]?

4. [D1]Did you ever tell even one liein the first 18 years of your life?

5. [R1]Did you ever have oral sex with [Victim 1]?

6. [R2]Did you ever put your penis in [Victim 1]'s genitals?

7. [D2] Prior to age 19, did you ever break even one rule or regulation?

8. [R3] Did you ever have oral sex with [Victim 2]?

9. [R4] Did you ever touch [Victim 2]'s anus with your penis?

10. [D3]Did you ever make even one mistake before the age of 19 ?

11. Do you live in [State]?

Two (2) victims and four (4) alleged crimes in one test format! Where is the research supporting a test with 2 victims and 4 crimes in a single test? Five charts were administered, with the examiner selecting the Comparison Question on either side of the pair of Relevant Questions that was strongest, leaning the score toward a truthful outcome. The examiner scores were as follows:

$\begin{array}{lc}\text { R1 } & +3 \\ \text { R2 } & 0 \\ \text { R3 } & \text {-3 } \\ \text { R4 } & +3\end{array}$

I scored these charts using the Horizontal Scoring System [1] and ASIT PolySuite [2] and obtained the following results:

$\begin{array}{llll}\mathrm{R} 1 & \mathrm{R} 2 & \mathrm{R} 3 & \mathrm{R} 4 \\ \mathbf{- 2 1} & \mathbf{- 2 3} & \mathbf{- 4 6} & \mathbf{- 1 2}\end{array}$

These same charts were blindly scored by four school directors and six government examiners. The examiners were only told that the test consisted of four different 
Relevant Questions. They had no idea what the questions were or who the original examiner was. All of the blind evaluators had determinations of deception.

No evaluator was told which scoring system to use (3- or 7-point)but just to score and report vertical scores and decisions using standard cut offs. They analysed 24 spots and determined 22 to be DECEPTIVE and 2 to be INCONCLUSIVE. The following were the scores of the six blind Government examiners:

\begin{tabular}{|c|c|c|c|c|c|}
\hline \multicolumn{2}{|c|}{ Examiner 1} & $\mathrm{R} 1$ & $\mathrm{R} 2$ & R3 & $\mathrm{R}$ \\
\hline-8 & -8 & -5 & +1 & & \\
\hline \multicolumn{2}{|c|}{ Examiner 2} & $\mathrm{R} 1$ & $\mathrm{R} 2$ & R3 & \\
\hline-3 & -9 & -10 & -8 & & \\
\hline \multicolumn{2}{|c|}{ Examiner 3} & $\mathrm{R} 1$ & $\mathrm{R} 2$ & R3 & \\
\hline+3 & -4 & -7 & -3 & & \\
\hline \multicolumn{2}{|c|}{ Examiner 4} & $\mathrm{R} 1$ & $\mathrm{R} 2$ & R3 & \\
\hline-5 & -4 & -7 & -6 & & \\
\hline \multicolumn{2}{|c|}{ Examiner 5} & $\mathrm{R} 1$ & $\mathrm{R} 2$ & R3 & \\
\hline+3 & -9 & -12 & -4 & & \\
\hline \multicolumn{2}{|c|}{ Examiner 6} & $\mathrm{R} 1$ & $\mathrm{R} 2$ & R3 & \\
\hline-3 & -2 & -9 & -5 & & \\
\hline
\end{tabular}

Fig. 1. The five (5) crime charts administered in Test 1 :

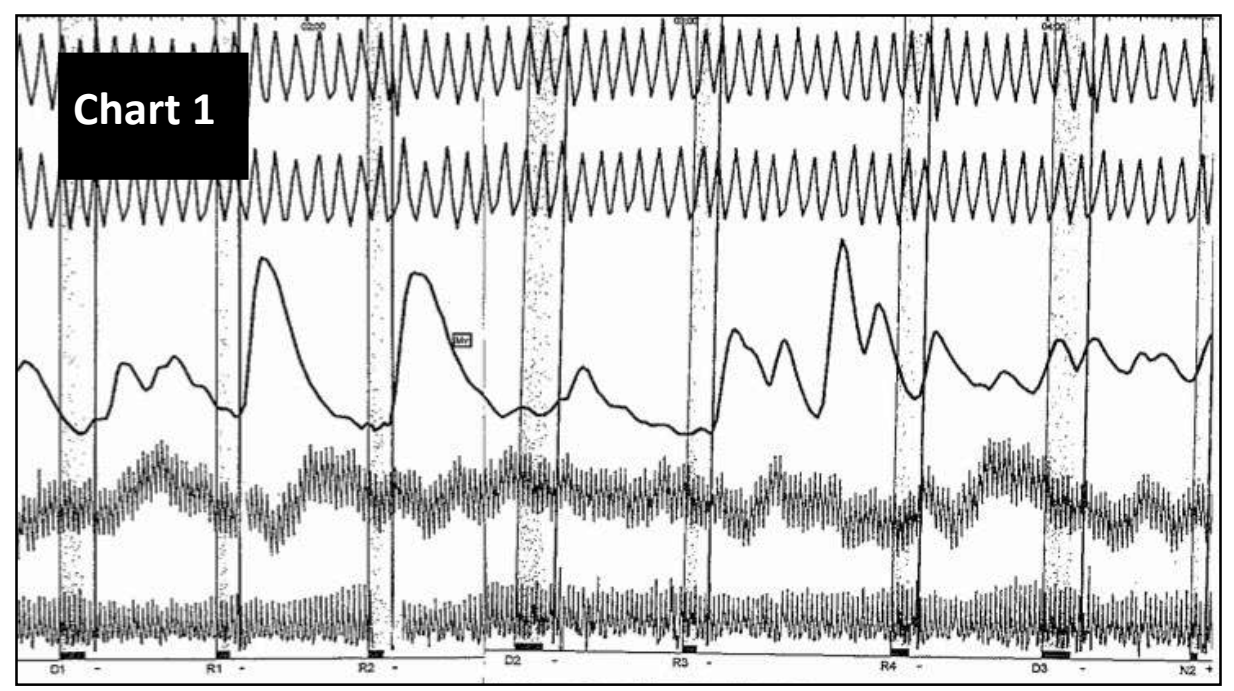



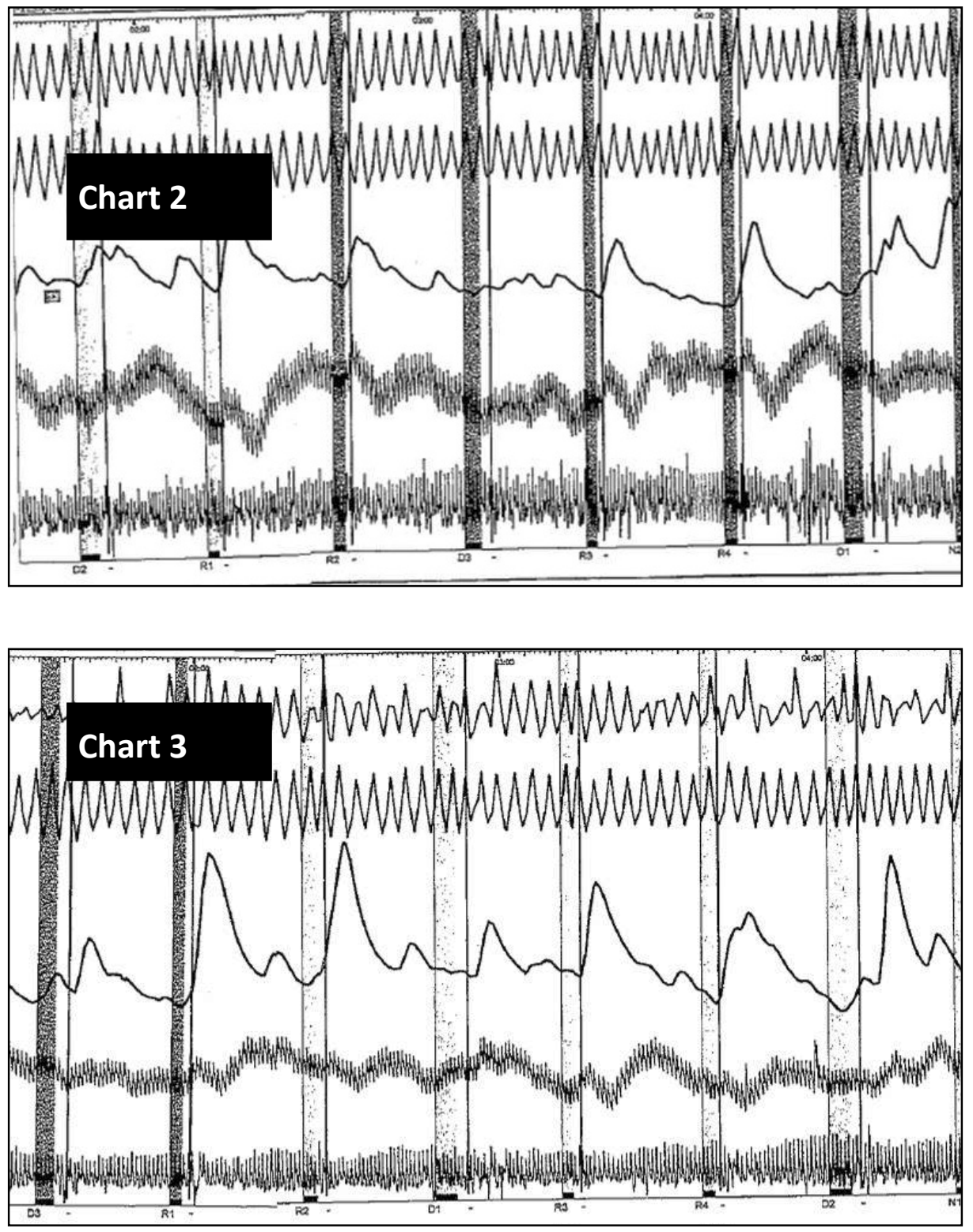

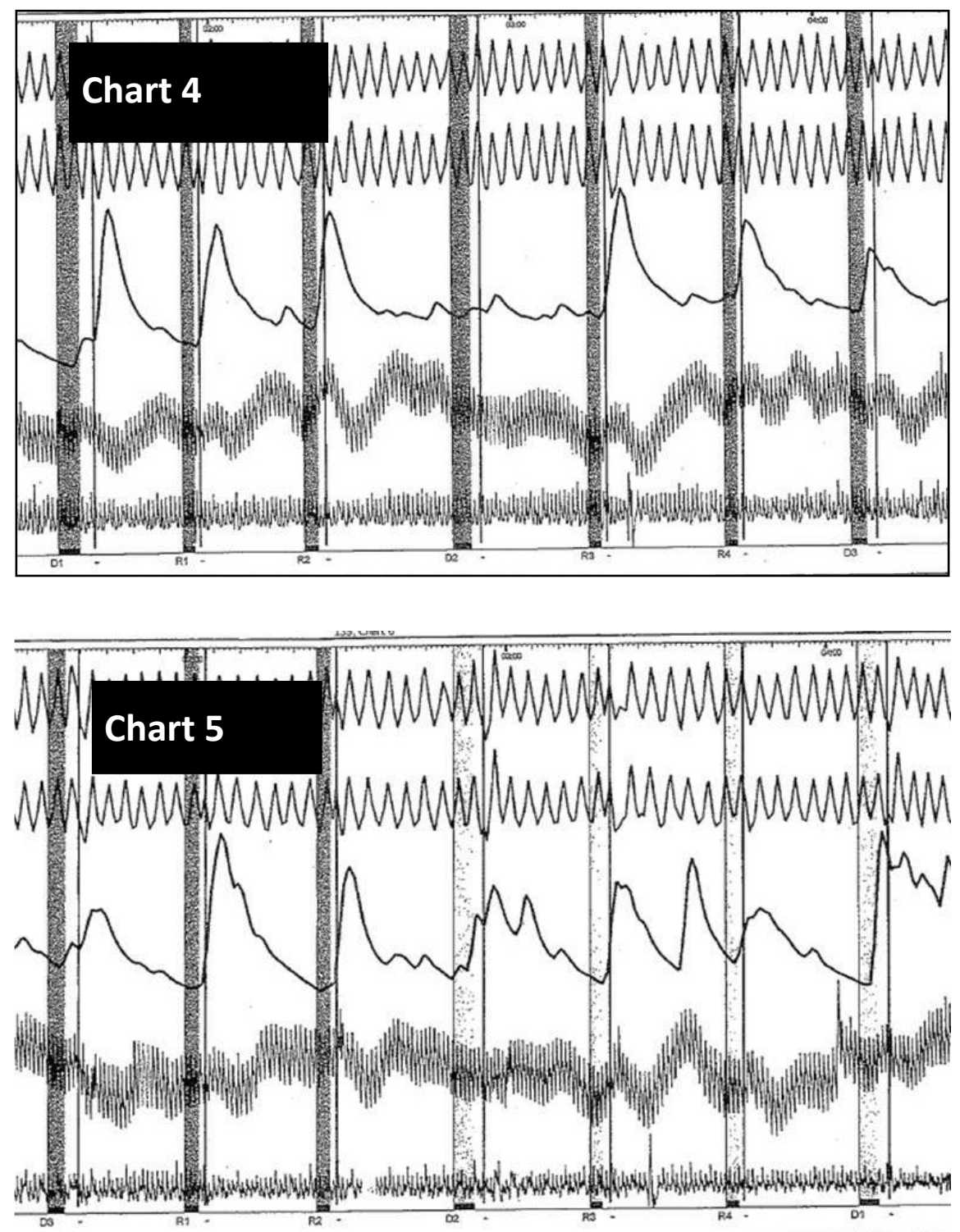

The blind evaluators made the following comments: some of the EDA responses are questionable. There seems to be movement at places that were ignored. There was no movement sensor used even though the test was administered after the APA deadline requiring its inclusion. 
The original examiner had a -3 at R3indicating a "Significant Response" and found the test inconclusive. What should have been the next step then? I would think you would use the generally accepted hurdle approach and run a more accurate single issue zone on R3, the Relevant Question that showed a "Significant Response". Instead, the examiner changed all of the DLCQs to Probable Lie Comparison Questions. We have no idea as to how the new "Comparison Questions" were introduced or stimulated. The Relevant Questions were slightly reworded but contained the same material. In this way three charts using the following questions were collected:

1. Do you understand I will ask only the questions we have discussed?

2. Do you intend to answer truthfully all the questions about allegations that you sexually abused [Victim 1] and [Victim 2]?

3. Is your last name [Name]?

4. PLC1.Did you ever engage in a sexual act that you were ashamed of during the first 20 years of your life?

5. R1.Did you ever have mouth to genital contact with [Victim 1]?

6. R2.Did you ever touch [Victim 1]'s genitals with your penis?

7. PLC2.Between the ages of 18 and 21, did you ever think about having sex with a minor?

8. R3.Did you ever have mouth to genital contact with [Victim 2]?

9. R4.Did you ever touch [Victim 2]'s anus with your penis?

10. PLC3.Did you ever take advantage of someone for sexual purposes before the age of 21 ?

11. Do you live in the United States?

With the following scores, the examiner decided to find the subject TRUTHFUL:

$\begin{array}{ll}\text { R1 } & +1 \\ \text { R2 } & +2 \\ \text { R3 } & +5 \\ \text { R4 } & +6\end{array}$

I scored these charts using the Horizontal Scoring System and ASIT Poly Suite and had the following results:

$\begin{array}{llll}\mathrm{R} 1 & \mathrm{R} 2 & \mathrm{R} 3 & \mathrm{R} 4 \\ \mathbf{- 1 6} & +2.5 & +9 & \mathbf{- 9 . 7 5}\end{array}$

These same charts were again blindly scored by four school directors and six government examiners. All the blind evaluators also had determinations of deception. I did not get to testify in the case because polygraph evidence was never introduced. The perpetrator plead guilty to all charges. 
Researched formats are fine; however formats in my mind are not aligned with polygraph techniques. There is much more to polygraph technique than just question structure.

Although some our fellow professionals wish polygraph to be pure science, it is not fully so. Polygraph is an art, based on principles drawn from the sciences of psychology and physiology. As a profession, we should continue research to validate what we are doing and to improve the art we practice. We cannot allow ourselves to be led down a path that misleads us to believe that what we do is purely a science that will eventually require examiners to possess doctorates to administer it. The skill of an examiner is an art, and it is just as important as the scientific aspects involved in polygraph. As this test clearly demonstrates, academic credentials do not equate to being an elite examiner any more than validating a question structure validates a polygraph technique.

\section{References}

[1] Gordon N., Cochetti P., The Horizontal Scoring System, Polygraph, 1987, 16, 2, pp. 118-125.

[2] ASIT PolySuite is a manually driven computerised algorithm for analysing polygraph data.

\section{Bibliography}

APA Ad-hoc Committee, Meta-Analytic Survey of Criterion Accuracy of Validated Polygraph Techniques, Polygraph 2011, 44 (4), pp. 194-305.

Gordon N., Cochetti P., The Horizontal Scoring System, Polygraph, 1987, 16, 2 , pp. 118-125.

Matte J.A., Forensic Psychophysiology, Using the Polygraph, J.A.M. Publications, 1996, Williamsville, NY, pp. 195-199. 
